\title{
O PRINCÍPIO DA INSIGNIFICÂNCIA SOB UM ENFOQUE JURISPRUDENCIAL
}

\author{
JEAN FERNANDES BARBOSA DE CASTRO
}




\title{
PRINCÍPIO DA INSIGNIFICÂNCIA SOB UM ENFOQUE JURISPRUDENCIAL
}

\author{
Jean Fernandes Barbosa de Castro'
}

\section{RESUMO:}

O presente trabalho científico versa sobre o princípio da insignificância em sua dimensão jurisprudencial emanada pelos tribunais superiores. No curso da estruturação do tema, será feita uma análise introdutória sobre as diretrizes principiológicas do direito penal, com breve acepção doutrinária, fazendo uma confluência do instituto com outros postulados. No plano de fundo da pesquisa, será feita uma abordagem sistemática da interpretação hodierna do Supremo Tribunal Federal e Superior Tribunal de Justiça ao redor do princípio, frente a diversos bens jurídicos tutelados pelo direito penal. $\mathrm{O}$ esteio do trabalho foi construído a partir de pesquisas realizadas na doutrina e na jurisprudência, concentrando-se o tema no direito penal.

Palavras-chave: Princípios de direito penal. Princípio da Insignificância. Natureza Jurídica. Elementos Estruturantes e Dogmáticos.

\section{ABSTRACT:}

This paper deals with the scientific principle of insignificance in the scale of jurisprudence emanating fron the courts. In the course of structuring the subject, Will be an introductory discussion about the guidelines of principles of criminal law, with a brief doctrinal meaning, making institute with a confluence of other postulates. In the background of the research Will be a systematic approach to today's interpretation of the Supreme Court and Superior Court of Justice around the principle against various legally protected by criminal Law. The mainstay the work was constructed from research conducted in

\footnotetext{
1 Juiz substituto do Estado de Tocantins, respondendo pela Vara Cível da Comarca de Taguatinga- TO. Foi Delegado de Polícia no Distrito Federal. Exerceu a Docência nas Faculdades IESGO, em Formosa - GO, onde lecionou as disciplinas de Direito Penal, Processual Penal, Direito Penal, Direito Civil e Processual Civil. E-mail: jeandecastro@tjto.jus.br
} 
the doctrine and jurisprudence, focusing on the issue in criminal law.

Keywords: Principles of criminal law. Principle of insignificance. Legal. Structuring element and dogmatic.

\section{INTRODUÇÃO}

O Direito Penal só deve se preocupar em tutelar a proteção dos bens jurídicos mais caros do ponto de vista do tecido constitucional. Essa premissa é fundada no princípio da intervenção mínima, ou ultima ratio, que comporta estreita correlação com o princípio da insignificância. Ao realizar essa tarefa seletiva de proteção, os demais bens jurídicos poderão ser amparados por outros ramos do ordenamento jurídico, por exemplo, o Direito Civil e o Direito Público. Daí, temos a equação do princípio da insignificância com o da fragmentariedade, igualmente estampado na teoria principiológica do Direito Penal. Ademais, os princípios da lesividade e da adequação social, também interferem no contexto do aprendizado do instituto matriz desta pesquisa, na medida em que justificam a atipicidade de algumas condutas, moldurando a insignificância, já que o primeiro limita o poder do legislador, dando importância apenas às condutas incriminadas pela lei penal, ao passo que o segundo, na precisa lição de Luiz Regis Prado, significa que,

(...) apesar de uma conduta se subsumir ao modelo legal não será considerada típica se for socialmente adequada ou reconhecida, isto é, se estiver de acordo com a ordem social

Revista Esmat, Palmas, Ano 3, n 3, pag. 57 a 73 - jan/dez 2011 
da vida historicamente condicionada $(\ldots)^{2}$

\subsection{Conceito}

Mas na verdade, o quê significa o princípio da insignificância e qual a sua origem?

Segundo preleciona Assis Toledo ${ }^{3}$, citado por Rogério $\mathrm{Greco}^{4}$,

(...) O princípio da insignificância se revela por inteiro pela sua própria denominação, por sua natureza fragmentária, só vai aonde seja necessário para a proteção do bem jurídico.

Não deve ocupar-se de bagatelas (...)

Cezar Bitencourt ${ }^{5}$ assevera que o princípio da insignificância foi escrito primitivamente por Claus Roxin em 1964, partindo do adágio latino mínima non curat praetor. Bitencourt (2008).

Em uma tentativa conceitual do instituto, podemos afirmar que o princípio da insignificância constitui um postulado segundo o qual faz emergir a exclusão da incidência do direito penal, consubstanciando um mecanismo de interpretação, frente a situações jurídicas desprovidas de lesividade de bens jurídicos

\footnotetext{
2 PRADO, Luiz Regis. Curso de direito penal brasileiro: parte geral. São Paulo: RT, 2008. p. 83

3 TOLEDO, Francisco de Assis. Princípios básicos de direito penal. São Paulo: Saraiva, 2006. p. 133

4 GRECO, Rogério. Curso de Direito Penal: vol.1. Niterói: Impetus, 2009.

5 BITENCOURT, Cezar Roberto. Tratado de Direito Penal: parte geral1. São Paulo: Saraiva, 2008.
} 
tutelados.

1.2 Elementos estruturantes e dogmáticos do princípio da insignificância

Decerto, é importante ressaltar, que o conceito da insignificância se assenta em três elementos, do ponto de vista estruturante:

- Elemento objetivo - O objeto material sobre o qual recai a infração aliado à conduta do agente;

- Elemento subjetivo - Os aspectos personalíssimos, segundo os quais consideram as condições pessoais do agente e da vítima;

- Elemento finalístico - O qual se concentra na seara de acepção do elemento anímico da vontade, de modo a examinar os motivos pelos quais a infração foi praticada;

Sem embargo dessa conotação, é certo que o Pretório Excelso edificou, a partir do majestoso estudo do Eminente Ministro Celso de $\mathrm{Melo}^{6}$, os elementos do princípio da insignificância, os quais pedimos vênia, para cognominá-los, de um ponto de vista dogmático:

- Mínima ofensividade da conduta;

- Ausência de periculosidade social da ação;

- Reduzido grau de reprovabilidade do comportamento;

- Inexpressividade da lesão jurídica;

(HC 84412/SP - DJ, 19/11/2004) 
A partir dessa diretriz, é imperativo ressaltar que dentre os contornos do postulado, há componentes objetivos e subjetivos. Assim, a irrelevância ou insignificância de determinada conduta, deve ser aferida de forma dinâmica, é dizer, além da importância do bem juridicamente tutelado e das consequências jurídicopenais da conduta, merecem ser objeto de reflexão, o grau de censura do comportamento e as características pessoais dos autores envolvidos na infração.

\section{VISÃO DO INSTITUTO SOB A ÓTICA DOS TRIBUNAIS SUPERIORES}

Tendo em conta essas balizas introdutórias, passamos ao estudo do tema na dimensão jurisprudencial.

Em uma vertente jurisprudencial, já se convencionou asseverar que o princípio da insignificância é um fator de descaracterização material da própria tipicidade penal ${ }^{7}$.

A Corte Suprema adotou também a orientação segundo a qual a aplicação do princípio há de ser criteriosa e casuística ${ }^{8}$.

\subsection{Reiteração de conduta delitiva, reincidência e princípio da insignificância}

Há controvérsia na Suprema Corte a respeito da aplicação do princípio da insignificância, no caso de reincidência ou

7 (HC 97836/RS, rel. Min. Celso de Mello, informativo 547-2 $2^{\mathrm{a}}$ Turma)

8 (HC 96.057-RS - Informativo 555) 
reiteração de conduta do agente.

A $1^{\text {a }}$ Turma, tem asseverado que a reincidência específica e a reiteração de conduta delitiva, constituem motivos suficientes a afastar a aplicação do princípio da insignificância, nesse sentido:

(...) Destacou-se estar-se diante de reiteração de conduta delitiva, pois o agente faria do descaminho seu meio de vida, daí a inaplicabilidade do referido postulado (...) (HC 97257, Rel. Min. Marco Aurélio, informativo 603).

E mais:

Reputou-se que, em razão da reincidência específica do paciente em delitos contra o patrimônio, inclusive uma constante prática de pequenos delitos, não estariam presentes os requisitos autorizadores para o reconhecimento desse postulado ${ }^{9}$ (HC 101998, rel. Min. Dias Toffoli, informativo 610).

A seu turno, a $2^{\mathrm{a}}$ Turma, possui dissenso entre os seus membros, contendo posição diametralmente oposta à $1^{\text {a }}$ Turma, admitindo o reconhecimento da insignificância mesmo em caso de $o$ agente possuir reiteração de condutas, bem como orientação que converge com a 1 Turma, in verbis:

Considerou-se, relativamente ao princípio da insignificância, não ser possível a análise dos elementos subjetivos desfavoráveis, mesmo que se trate de reiteração 
de conduta. Afirmou-se, ainda, que o referido postulado, afetaria a própria tipicidade penal ${ }^{10}$. (HC 104468, rel. Min. Gilmar Mendes, informativo 606).

Em recente julgado, a $2^{\mathrm{a}}$ Turma deferiu ordem de habeas corpus para trancar ação penal, após empate na votação. O caso posto a desate seria de um condenado reincidente, que cumpria pena em regime semi-aberto, pelo furto tentado de bem avaliado em R\$ 70,00 (setenta reais). ${ }^{11}$

Há posicionamento recente do Sodalício Superior, por maioria, assentando que a habitualidade da conduta tida por criminosa descaracteriza sua insignificância. ${ }^{12}$

\subsection{Princípio da insignificância e característica especial do agente}

É consabido que o sistema penal brasileiro adotou o direito penal do fato, pelo que se pune o autor da conduta delituosa pelo que ele fez e não pelo que é. Entretanto, há outra perspectiva a considerar o autor da conduta e não o fato para análise de sua responsabilização penal. Aqui, estamos diante do direito penal do autor, adotado como exceção no nosso ordenamento, como no caso de fixação da pena e do regime de cumprimento da

\footnotetext{
10 (HC 104468, rel. Min. Gilmar Mendes, informativo 606).

11 HC 106510/MG, rel. orig. Min. Joaquim Barbosa, red. Para o acórdão Min. Celso de Mello, 22.3.2011.

12 HC 196.132-MG, Rel. Min. Napolião Nunes Maia Filho, 10/05/2011, informativo $472-5^{\text {a }}$ Turma.
} 
sanção (CP, art. 59).

Assentado nessa premissa, os tribunais superiores parecem dar um colorido especial à matéria, criando nova exceção ao modelo, quando do reconhecimento do postulado da insignificância. A ideia é a de criar obstáculos à aplicação do princípio, quando o envolvido possui característica especial, cuja reprovação da conduta não permita a imposição do preceito.

\subsubsection{Policial}

No caso de envolvimento de policial, tem-se firmado que não é permitido o emprego da insignificância, ante o alto grau de reprovação na conduta, sendo ela relevante para o direito penal.

Nesse aspecto:

Vê-se, assim, não ser possível aplicar o princípio da insignificância à hipótese, visto não estarem presentes todos os requisitos necessários para tal. Apesar de poder tachar de inexpressiva a lesão jurídica em razão de ser ínfimo o valor dos bens subtraídos ( $\mathrm{R} \$ 0,40)$, há alto grau de reprovação na conduta do paciente, além de ela ser relevante para o Direito Penal; pois aos olhos da sociedade, o policial militar representa confiança e segurança, dele se exige um comportamento adequado, dentro do que ela considera correto do ponto de vista ético e moral. ${ }^{13}$ 


\subsubsection{Prefeito}

Sendo o sujeito ativo do delito prefeito, também existe resistência à aplicação do instituto. In casu, não se olvida que a interpretação se refere ao delito praticado no exercício da função.

Vejamos:

A turma, entre outras questões, entendeu ser inaplicável o princípio da insignificância aos crimes praticados por prefeito, em razão de sua responsabilidade na condução dos interesses da coletividade. A conduta esperada de um chefe da Administração municipal é a obediência aos mandamentos legais, com a obrigatoriedade de agir sempre pautado em valores éticos e morais, respeitando os compromissos funcionais firmados quando da aceitação do cargo. ${ }^{14}$

Registre-se, contudo, que já se admitiu a incidência do postulado em caso de utilização de máquinas e caminhões de prefeitura por ex-prefeito, em terraplanagem no terreno de sua propriedade, desprezando-se a orientação acima aventada. ${ }^{15}$

\subsubsection{Preso}

Tem asseverado o Colendo Superior Tribunal de Justiça, que na hipótese de crime perpetrado nas dependências de penitenciária por preso que cumpre pena, não há que

14 HC 145.114 , rel. Min. Jorge Mussi, informativo 443 STJ.

15 HC 104286/SP - São Paulo. STF 
se falar na aplicação da insignificância, face o alto grau de reprovabilidade da conduta. Nesse aspecto, o núcleo essencial para a inaplicabilidade é a ausência de um dos vetores a permitir o reconhecimento da atipicidade, qual seja, reduzidíssimo grau de reprovabilidade do comportamento.

STJ:

(...)

Na hipótese em apreço, embora o valor do objeto furtado (cartucho de tinta para impressora) possa ser considerado ínfimo, eis que avaliado em R\$25,70, o fato de pertencer ao Centro de Progressão Penitenciária onde o paciente cumpre a pena por delito anterior denota o alto grau de reprovabilidade da conduta, afastando a possibilidade de incidência do referido princípio ao caso concreto. Precedentes do STJ.

\subsubsection{Infrações de contrabando e descaminho}

Em julgamento de recurso repetitivo (art. 543-C do CPC e Res. N. 8/2008-STJ), entendeu-se o STJ que, em atenção à jurisprudência predominante da Suprema Corte, deve-se aplicar o postulado da insignificância ao crime de descaminho quando os delitos tributários não ultrapassem o limite de R\$ 10 mil, adotando-se o disposto no art. 20 da Lei n ${ }^{\circ} 10.522 / 2002 .{ }^{16}$

Ocorre que há julgado do mesmo Tribunal, limitando a aplicação da insignificância apenas nas hipóteses de valores no patamar de cem reais, entendimento prevalente no âmbito da Quinta Turma do STJ, ao argumento de que o vetor de R\$

16 Informativo 406-3 $3^{\text {a }}$ Seção do STJ. 
10 mil aplica-se apenas no caso de arquivamento, sem baixa na distribuição, da ação de execução fiscal (suspensão da execução), o que denotaria, em tese, sua inaptidão para caracterizar o que deve ser penalmente irrelevante. ${ }^{17}$

Em que pese a distinção jurídica entre as figuras penais, caracterizando o contrabando a primeira parte do art. 334 do Código Repressivo (importar ou exportar mercadoria proibida), e lado outro o descaminho, contido no verbo reitor iludir, contido na segunda parte da norma incriminadora, certo é que o tratamento para fins de aplicação da insignificância é linear pelos tribunais superiores.

Por óbvio, seguindo-se a mesma sistemática, nada obsta que se aplique o preceito da insignificância aos crimes contra o sistema financeiro nacional, previstos na lei $n^{\circ} 7.492 / 1986$, também conhecida como lei do colarinho branco, desde que a lesão ao sistema financeiro seja considerada insignificante.

\subsubsection{Roubo}

Parece estar consolidado o entendimento no sentido de ser incabível a aplicação do instituto estudado no contexto do delito de roubo. In casu, malgrado a hipótese de ínfimo valor do bem subtraído, fatores outros justificam repelir a sua incidência em casos tais, eis que a conduta não denota com mínima ofensividade, além de que, sobrevive a periculosidade da ação e 
a reprovação do comportamento, em um ângulo objetivo.

\subsubsection{Fé Pública}

De se ver que não se tem admitido a incidência do prima principium no âmbito dos delitos cuja objetividade jurídica seja a Fé Pública.

A vedação é justificável, do ponto de vista teórico, já que o bem jurídico tutelado, leia-se, a fé pública, é um bem intangível, imaterial, não sendo por isso quantificável. Em arremate, se estuda o plano da conduta e não do valor economicamente auferido pela atividade criminosa.

Esse entendimento é abraçado pela jurisprudência pretoriana, vejamos:

(...) Enfatizou-se, ademais, que o bem violado seria a fé pública, a qual é um bem intangível e que corresponde à confiança que a população deposita em sua moeda, não se tratando, assim, da simples análise do valor material por ela representado $(\ldots)^{18}$

Nesse mesmo sentido, posiciona-se a jurisprudência do STJ.

\subsubsection{Usuário de drogas}

A Suprema Corte tem censurado também a aplicação do

HC 96153/MG, rel.Min. Carmen Lúcia, 26.5.2009. Informativo $548-1^{\mathrm{a}}$ Turma

Revista Esmat, Palmas, Ano 3, $\mathrm{n}^{\circ} 3$, pag. 57 a 73 - jan/dez 2011 
instituto ao usuário de drogas, em face da real possibilidade de o usuário vir a se tornar mais um traficante, em busca de recursos para sustentar seu vício. Observam, ainda, não se poder falar em ausência de periculosidade social da ação, como um dos elementos dogmáticos para a verificação da insignificância. Pela nossa pesquisa, a orientação ainda está pendente de análise pelo Plenário do STF. ${ }^{19}$

Do mesmo modo, por reputar incompatível com a relação jurídica existente entre o usuário de pequena quantidade de droga e a instituição militar da qual ele faz parte, o Supremo Tribunal Federal decidiu pela inaplicabilidade do princípio da insignificância em relação às hipóteses arroladas no art. 290 do Código Penal Militar. É dizer: tal premissa se coaduna com os fins precípuos existentes na disciplina castrence, exigindo-se dos militares comportamento compatível com a função por eles exercida.

\subsubsection{Infância e Juventude}

De se ver, ainda, não haver incompatibilidade material ou formal do preceito da insignificância para com os ditames do Estatuto da Criança e do Adolescente, no caso da prática de atos infracionais. Tal como exposto, uma vez presentes os elementos do postulado, aplica-se a insignificância nas condutas que se inserem na categoria de atos infracionais.

$\overline{19 \quad \text { Informativo }} 597$. 


\section{CONSIDERAC ÕES FINAIS}

Considerado um prima principium do Direito Penal, nos últimos anos o princípio da insignificância vem ganhando plano de destaque na jurisprudência dos Tribunais Superiores. $\mathrm{O}$ preceito é um dos fundamentos mais utilizados no âmbito dos pedidos envolvendo habeas corpus, em que pese esteja consolidado que a via não é a mais adequada à aferição dos seus requisitos, em que é vedado o profundo exame do contexto fático-probatório.

Destarte, considerando a sua importância no estudo do juízo da tipicidade, cabem aos operadores do direito e intérpretes da norma penal, delimitarem o âmbito de abrangência dos tipos penais abstratamente positivados no ordenamento jurídico criminal, excluindo do seu campo de atuação aqueles considerados de pequena expressão, frente ao bem jurídico tutelado, onde cabível a incidência do postulado da insignificância.

A análise casuística é a melhor premissa para a aferição da presença de pressupostos necessários à exclusão da tipicidade pela insignificância, quando patente os seus elementos estruturantes e dogmáticos.

É cediço, entretanto, que se arvoreceu uma moldura onde se amoldam determinadas situações jurídicas reconhecidamente consolidadas pela insinificância, a partir da evolução jurisprudencial dos Tribunais Superiores, prestigiando a isonomia e a segurança jurídica no âmbito penal.

Em suma, o postulado representa um dos pilares à 
interpretação da norma penal, sendo vital para o estudo da tipicidade, ratio essendi da antijuridícidade.

\section{REFERÊNCIAS BIBLIOGRÁFICAS}

AGUIAR, Alexandre Magno Fernandes Moreira. O princípio da insignificância e os crimes contra o sistema financeiro nacional. Jus Navigandi. Teresina, ano 9. N. 255, 19 mar. 2004.

BITENCOURT, Cezar Roberto. Tratado de Direito Penal. Parte Geral 1. São Paulo: Editora Saraiva, 2008

GALVÃO, Fernando. Direito Penal. Parte Geral. Belo Horizonte: Editora Del Rey, 2007.

GOMES, Luiz Flávio. Direito Penal. Parte Geral. São Paulo: Editora RT, 2004.

GRECO, Rogério. Curso de Direito Penal. Vol. 1. São Paulo: Editora Ímpetus, 2009.

MASSON, Cléber. Direito Penal. Vol. 1. São Paulo: Editora Método, 2008.

PRADO, Luiz Regis. Curso de direito penal brasileiro - Parte geral.São Paulo. Editora RT, 2008. 
TOLEDO, Francisco de Assis. Princípios básicos de direito penal. Editora Saraiva, 2006.

ZAFFARONI, Eugênio Raul e PIERANGELI, José Henrique. Manual de Direito Penal Brasileiro. Vol. 1. São Paulo: Editora RT, 2006. 